\title{
Measurement of material properties of composites under high temperature using fiber Bragg grating sensors
}

\author{
D. H. Kang ${ }^{1}$, S. W. Park ${ }^{1}$ S. H. Kim ${ }^{1}$, C. G. Kim ${ }^{1 *}$ and C. S. Hong ${ }^{1}$ \\ ${ }^{1}$ Division of Aerospace Engineering, Korea Advanced Institute of Science and Technology, 373-1, \\ Kuseong-dong, Yuseong-gu, Daejeon, 305-701, Korea \\ $1^{1 *}$ Author to whom any correspondence should be addressed (cgkim@kaist.ac.kr)
}

Keywords: High Temperature, Composites, Fiber Bragg Grating, Material Properties

\begin{abstract}
Composites are widely used for aircraft, satellite and other structures due to their good mechanical and thermal characteristics such as low coefficient of thermal expansion (CTE), heat-resistance, high specific stiffness and strength. However, in order to use composites under condition of high temperature, material properties of composites at high temperature must be measured and verified. In this paper, material properties of T700/Epoxy were measured through tension test of composite specimens with an embedded FBG sensor in the thermal chamber at the temperatures of RT, $100^{\circ} \mathrm{C}, 200^{\circ} \mathrm{C}, 300^{\circ} \mathrm{C}$ and $400^{\circ} \mathrm{C}$. Through the pre-test of embedded optical fiber, we confirmed the embedding effects of optical fiber on material properties of the composites. Two kinds of specimens of which stacking sequences are $[0 /\{0\} / 0]_{\mathrm{T}}$ and $\left[90_{2} /\{0\} / 90_{2}\right]_{\mathrm{T}}$ were fabricated. From the experimental results, material property changes of composites were successfully shown according to the temperatures and we confirmed that fiber Bragg grating sensor is very appropriate to strain measurement of composites under high temperature.
\end{abstract}

\section{Introduction}

Recently, composite materials are increasingly being used as engineering materials in aircrafts, buildings, and other structures due to the advantages such as high specific stiffness and strength, low coefficient of thermal expansion and good heat-resistance characteristics compared with the conventional aluminum alloys. However, composite materials can also be locally heated to high temperature owing to aerodynamic heating during the working condition. In this case, composite materials available at high temperature are needed and several researches related on them are conducted [1,2]. Though composite materials available at high temperature are composed of the matrix which can endure higher temperature than general composites, degradation of material properties also occurs with temperature increase. For the reason, the study on the change of material properties with temperature should be verified for the exact application of composite materials under high temperature.

Generally electric strain gages are mainly used to measure the material properties of composite materials because of the advantages such as low cost and convenience of use. But, there can be some problems on the adhesion between the gage and the specimen when the specimen is under high temperature and some limitations on the strain measurement when the temperature is very high. Besides, the strain gage also needs bridge circuit in order to compensate the thermal strain of the gage itself. However, fiber optic sensors are easy to embed into composites for the reason of small size, wide temperature ranges, electromagnetic immunity and good resistance to corrosion. Of many fiber optic sensors, fiber Bragg grating(FBG) sensors have good multiplexing capabilities and so they are 
being used for many researches on the strain measurement of composite structures [3] and applications under various temperature conditions [4,5]. From many advantages of FBG sensors previous mentioned, they are considered very appropriate as strain sensors under high temperature conditions and their application fields are gradually being expanded.

In this research, we measured the change of material properties of T700/Epoxy composite materials which were used to fabricate filament wound pressure tanks [6] at the temperatures of RT, $100^{\circ} \mathrm{C}, 200^{\circ} \mathrm{C}, 300^{\circ} \mathrm{C}$ and $400^{\circ} \mathrm{C}$ using FBG sensors. Two kinds of the specimens of which stacking sequences were $[0 /\{0\} / 0]_{\mathrm{T}}$ and $\left[90_{2} /\{0\} / 90_{2}\right]_{\mathrm{T}}$ were fabricated and the material properties were measured through tension tests in thermal chamber using an embedded FBG sensor which is inside the center of each specimen. And we also confirmed the embedding effects of optical fiber on material properties of the composites through the pre-test of embedded optical fiber. From the experimental results, material property changes of composites were successfully shown according to the temperature increase.

\section{Fiber Bragg grating sensor}

The fiber Bragg grating is periodic changes of refractive index that are formed in the core of an optical fiber by the exposure of an intense UV interference pattern. This grating structure results in the reflection of the light at a specific narrowband wavelength, called the Bragg wavelength. The Bragg condition is given by $\lambda_{B}=2 n_{e} \Lambda$ where $\lambda_{B}$ is the Bragg wavelength of FBG, $n_{e}$ is the effective index of the fiber core, and $\Lambda$ is the grating period. The wavelength which is determined by the Bragg condition reflects at the Bragg grating part and the other wavelengths pass through it. The Fig. 1 shows this process.

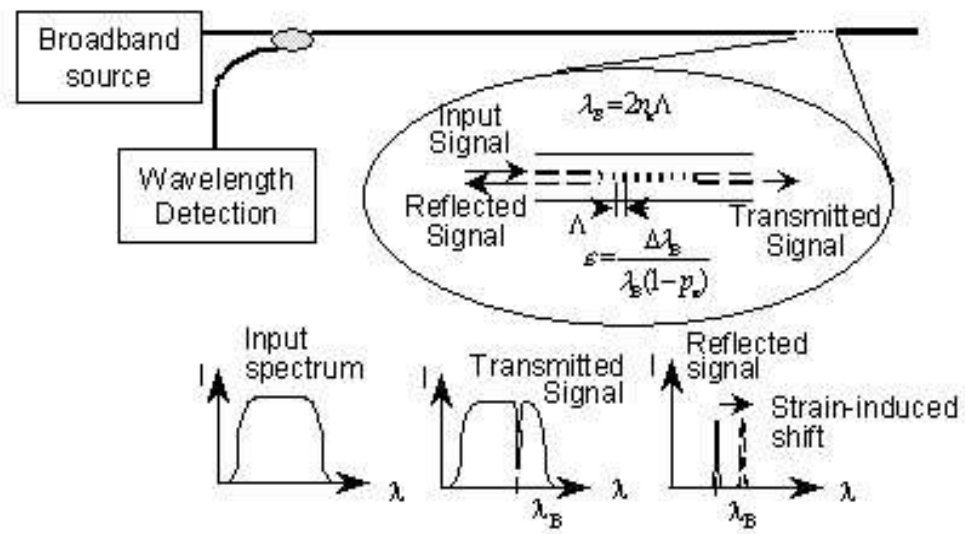

Fig. 1 Fiber Bragg grating sensor wavelength-encoding operation.

In the Bragg condition, the Bragg wavelength is a function of the effective index of the fiber core and the grating period. If the grating is exposed to the external environment such as strain and temperature, the Bragg wavelength changes. By measuring the wavelength change accurately, we can measure material properties like strain and temperature and this is the fundamental principle that fiber Bragg grating can be used as a sensor. The shift of Bragg wavelength due to strain and temperature can be expressed as

$$
\Delta \lambda_{B}=\lambda_{B}\left[\left(\alpha_{f}+\xi_{f}\right) \Delta T+\left(1-p_{e}\right) \varepsilon\right\rfloor
$$

where $\alpha_{f}$ is the coefficient of thermal expansion (CTE), $\xi_{f}$ is the thermo-optic coefficient, and $p_{e}$ is the strain-optic coefficient of the optical fiber. The value of $p_{e}(=0.227)$ was measured experimentally 
and used for this study. If there is no temperature change, we can measure the strain from the wavelength shift as

$$
\varepsilon=\frac{1}{1-p_{e}} \frac{\Delta \lambda_{B}}{\lambda_{B}}
$$

From the Eq. 2, the strain can be easily calculated just by measuring the wavelength shift. Also, we can measure the strains at many positions in single optical fiber by multiplexing capabilities of FBG sensors because FBG sensors which have different Bragg wavelengths don't influnce one another. In this research, we used a FBG sensor for each specimen and it was embedded into the specimen to measure the material properties.

\section{Embedding effects estimation of optical fiber}

Optical fiber has a certain size though it is very small, so it can affect material properties of composite materials when it is embedded into composites. For the verification of embedding effects of optical fiber on material properties, three types of specimens were fabricated. One is a normal tension test specimen in order to use its measurement data as a reference of material properties. The others are specimens that their ingress/egress types are stainless tube and PVC(polyvinyl chloride) jacket for the protection of optical fiber, respectively. The diameter of stainless tube was $0.6 \mathrm{~mm}$, the laminate was made of CU-125 NS graphite/epoxy prepreg (HFG Co.) and the stacking sequence of the laminate was chosen as $\left[0_{8}\right]_{\mathrm{T}},\left[90_{16}\right]_{\mathrm{T}}$.

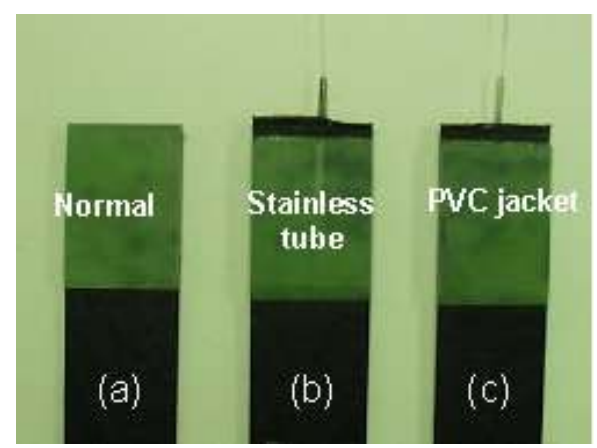

Fig. 2 Verification test specimens of the sensor embedding affection.

After the fabrication of test specimens, the adequate ingress/egress method was decided. In the case of stainless tube, some irregularities were observed on the surface of specimens as shown in Fig. 2. Thus, it was needed to make a groove on the tab surface when attaching tabs on the specimen. This process affected the adhesion strength between tab and surface of the specimen only to induce the separation between them. However, in the case of PVC jacket, it was kindly assimilated with composite materials during cure and showed no irregularities on the surface of the specimen after fabrication of test specimens.

Table 1 The results of verification test of sensor embedding

\begin{tabular}{|c|c|c|c|c|c|c|c|c|c|}
\hline \multirow{2}{*}[\mathbf{0}_{8}]{$_{\mathbf{T}}$} & \multicolumn{2}{|c|}{$\begin{array}{l}\text { Stiffness } \\
\text { [GP a] }\end{array}$} & \multicolumn{2}{|c|}{$\begin{array}{l}\text { Strength } \\
\text { [MP a] }\end{array}$} & \multirow{2}{*}[\mathbf{90}_{16}]{$_{T}$} & \multicolumn{2}{|c|}{$\begin{array}{l}\text { Stiffness } \\
\text { [GP a] }\end{array}$} & \multicolumn{2}{|c|}{$\begin{array}{l}\text { Strength } \\
\text { [MP a] }\end{array}$} \\
\hline & Aug. & Stder & Aurg. & Stdev. & & Aing. & Stder. & Aurg. & Stder. \\
\hline Nor mal & 132.3 & 1.35 & 2145 & 43.7 & Nor $\mathrm{ma}$ & 8.75 & 0.18 & 44.4 & 1.40 \\
\hline $\begin{array}{l}\text { PVC } \\
\text { jacke }\end{array}$ & 132.8 & 1.21 & 2214 & 40.0 & $\begin{array}{l}\text { PVC } \\
\text { jackt }\end{array}$ & 8.56 & 021 & 44.6 & 1.85 \\
\hline $\begin{array}{c}\text { Stainless } \\
\text { tube }\end{array}$ & 131.9 & 2.02 & 2199 & 45.4 & $\begin{array}{c}\text { Stairiess } \\
\text { tube }\end{array}$ & 864 & 024 & 45.4 & 2.67 \\
\hline
\end{tabular}


Tension test results of above specimens were conducted using electric strain gages (FLA-5-11, TML) and were shown in Table 1. From the results of table 1, we could conclude that PVC jacket is the best choice of ingress/egress method for embedding sensors without any degradation of material properties if we also considered the effectiveness of fabrication.

\section{Fabrication of test specimens}

The curing cycle of the T700/Epoxy specimen was shown in Fig. 3. There were some characteristics in curing cycle such as high temperatures and long duration time of $1^{\text {st }}$ holding and $2^{\text {nd }}$ holding step. The fabrication process of specimens was as follows in detail. After hoop winding on the mandrel was performed using reinforcing fiber (T700) with epoxy resin (MY0510, HFG Co.), the prepreg tape was finally made by spreading sheets extracted from the cylinder part and performing $\beta$-stage cure of them in a thermal chamber.

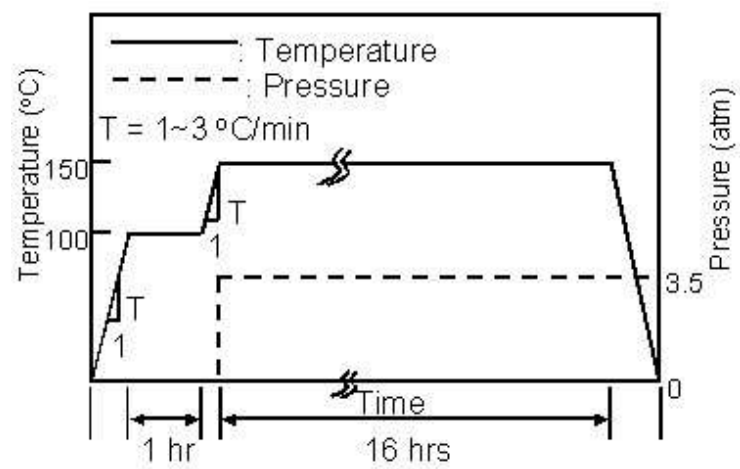

Fig. 3 Curing cycle of T700/Epoxy specimen.

Using these prepreg tapes, test specimens were fabricated in a autoclave molding and the staking sequences of the laminate were $[0 /\{0\} / 0]_{\mathrm{T}}$ and $\left[90_{2} /\{0\} / 90_{2}\right]_{\mathrm{T}}$ where ' \{\} ' marks the location and the figure in ' \{\} ' marks direction of an embedded sensor. One FBG sensor was embedded parallel to the reinforcing fiber in the $[0 /\{0\} / 0]_{\mathrm{T}}$ specimen and perpendicular to the reinforcing fiber in the $\left[90_{2} /\{0\} / 90_{2}\right]_{\mathrm{T}}$ specimen. Specimens were fabricated in terms of ASTM D 3039/D 3039M. The grating part of fabricated FBG sensor was recoated with arcylate using recoating machine and the end of each specimen was protected with PVC jacket mentioned in the previous section.

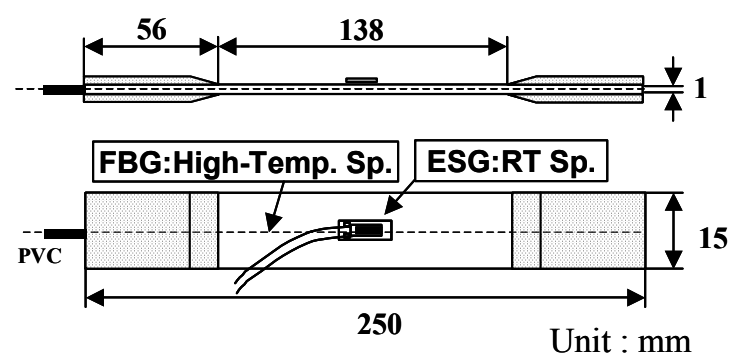

(a) $[0 /\{0\} / 0]_{\mathrm{T}}$

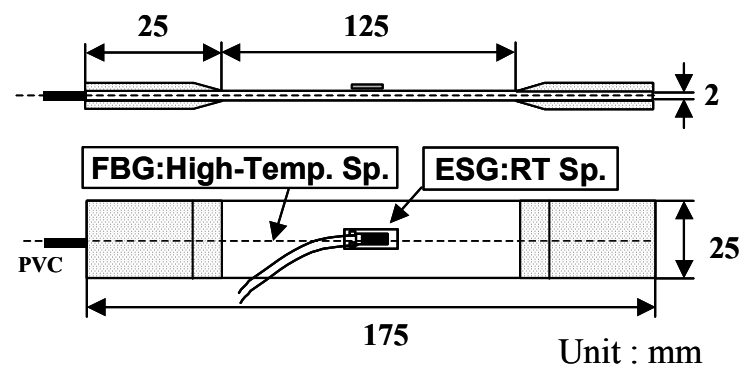

(b) $\left[90_{2} /\{0\} / 90_{2}\right]_{\mathrm{T}}$

Fig. 4 Configurations of the test specimens.

Two kinds of specimens, $0^{\circ}$ specimens and $90^{\circ}$ specimens, were fabricated and each specimen was also divided by five ones with temperatures such as RT, $100^{\circ} \mathrm{C}, 200^{\circ} \mathrm{C}, 300^{\circ} \mathrm{C}$ and $400^{\circ} \mathrm{C}$. Because every specimen was extracted from the same laminate in order to diminish the fabrication errors, the number of each kind of specimen was limited to two. The configurations of specimens and positions of sensors were shown in Fig. 4. An ESG was attached on the surface of RT specimen and a FBG 
sensor was embedded into every high-temperature specimen. The measured data from ESG was used as a reference of material properties and the property changes were characterized using the data from FBG sensors. The reflected signals of FBG sensors were acquired through a DAQ board, processed and saved by a signal-processing program written in LabVIEW ${ }^{\circledR}$ software [7]. A wavelength-swept fiber laser (WSFL) [8] was used as a broadband light source to supply high signal power. The sensor signals were acquired at $5 \mathrm{~Hz}$ intervals.

\section{Measurement of material properties at high temperature : $0^{\circ}$ specimens}

Tension test of $0^{\circ}$ specimens was conducted. The experimental data measured at room temperature was used as a reference of material properties. Test was performed using an electric strain gage(FLA-5-11-1L, TML) attached on the surface. However, the experimental data measured at high temperature such as $100^{\circ} \mathrm{C}, 200^{\circ} \mathrm{C}, 300^{\circ} \mathrm{C}$ and $400^{\circ} \mathrm{C}$ was achieved with a $\mathrm{FBG}$ sensor embedded into specimens. All tests were performed in the thermal chamber equipped at instron 4505 with displacement control of $1 \mathrm{~mm} / \mathrm{min}$. The experimental arrangement for the tension test of composite specimens under high temperature is depicted in Fig. 5.
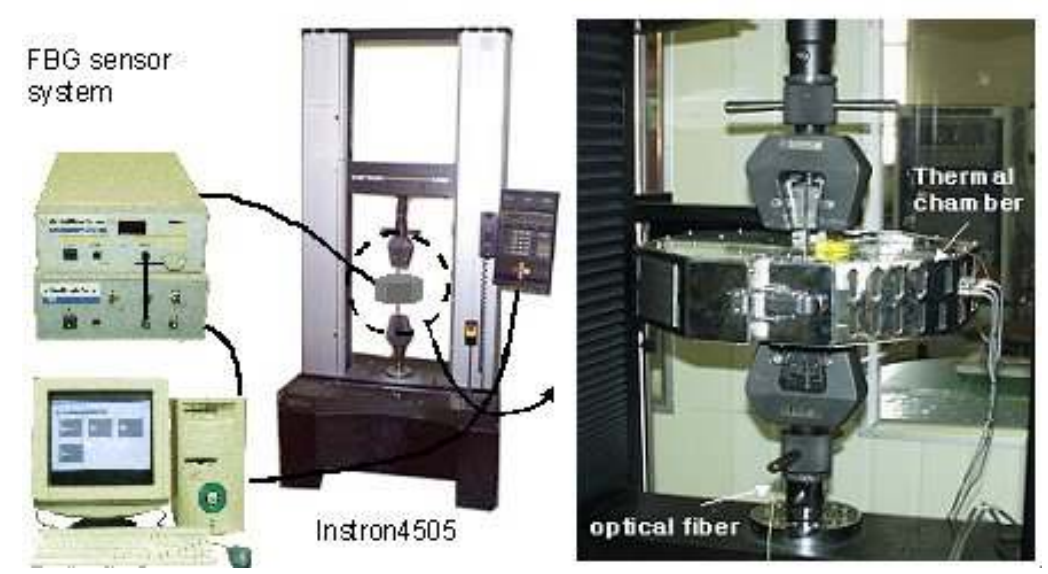

Fig. 5 Experimental setup of tension test at high temperatures.

In Fig. 5, test specimen was fixed on the grip of instron and the temperature of thermal chamber was set as the wanted temperature. Tension test was conducted after the setting temperature was completely held. The test results of specimens were shown in table 2 .

Table 2 Material properties of $\left[0_{2}\right]_{\mathrm{T}}$ at high temperatures

\begin{tabular}{|c|c|c|c|c|c|c|c|c|c|c|}
\hline \multirow{2}{*}[\mathbf{0}_{2}]{$_{T}$} & \multicolumn{2}{|c|}{ RT } & \multicolumn{2}{|c|}{$100{ }^{\circ} \mathrm{C}$} & \multicolumn{2}{|c|}{$200^{\circ} \mathrm{C}$} & \multicolumn{2}{|c|}{$300^{\circ} \mathrm{C}$} & \multicolumn{2}{|c|}{$400^{\circ} \mathrm{C}$} \\
\hline & Ang. & Stdev. & Ang. & Stdev. & Aang. & Stdev. & Ang. & Stdev. & Ang. & Stdev. \\
\hline $\begin{array}{c}\text { Stiffness } \\
{[\mathrm{GPa}}\end{array}$ & 141.6 & 6.74 & 1428 & 191 & 1462 & 0.35 & 117.4 & 2.33 & 845 & 29.49 \\
\hline $\begin{array}{l}\text { Strength } \\
\text { [MP a] }\end{array}$ & 1930 & 148.5 & 1760 & 849 & 1731 & 73.5 & 1724 & 31.3 & 1420 & 156.3 \\
\hline
\end{tabular}

In order to understand the tendency of material property changes, the results of table 2 were illustrated in Fig. 6. The stiffness was maintained from RT to $200^{\circ} \mathrm{C}$ and decreased over $200^{\circ} \mathrm{C}$. On the other hand, the strength decreased from RT to $100^{\circ} \mathrm{C}$ and was maintained from $100^{\circ} \mathrm{C}$ to $300^{\circ} \mathrm{C}$. Over $300^{\circ} \mathrm{C}$, it decreased again. As shown in Fig. 6, stiffness and strength showed a different tendency with temperature each other. 

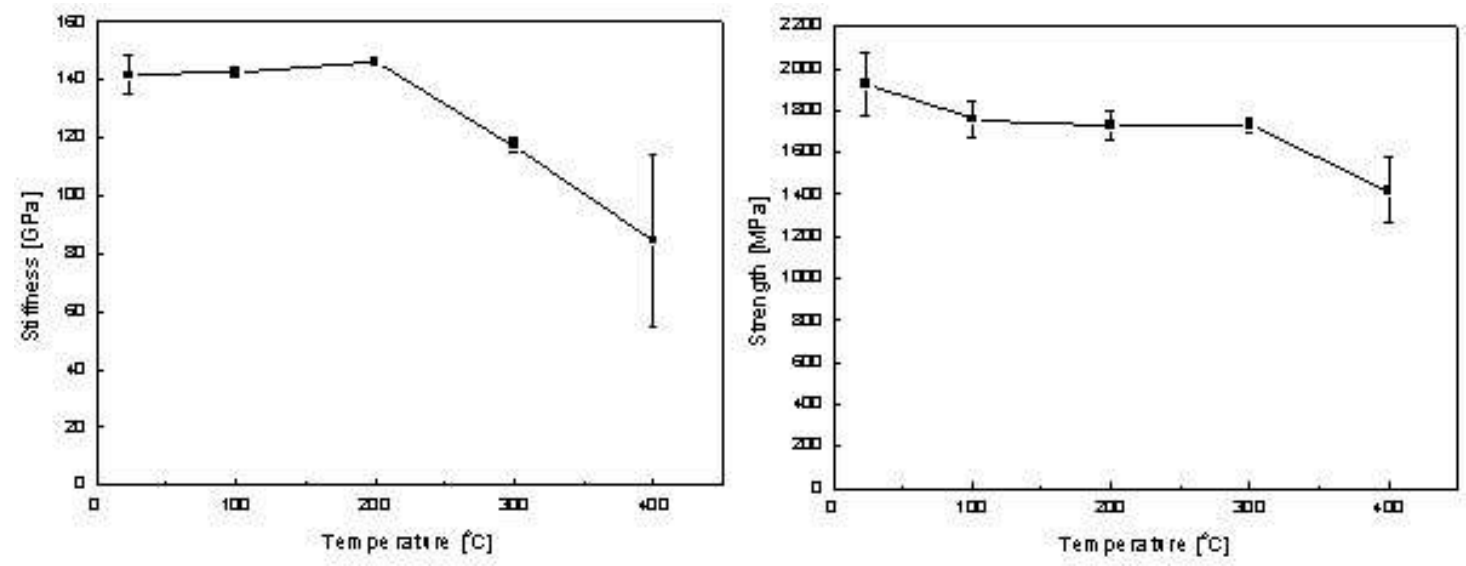

Fig. 6 Material property change of $\left[0_{2}\right]_{\mathrm{T}}$ with temperatures.

In Fig. 6, there was a characteristic that the measured data showed a large deviation. For the causes of a large deviation, it was thought of the irregularity of specimens. In order to confirm the irregularities, the microphotographs of the cut end of T700/epoxy specimen were compared with those of graphite/epoxy specimen. Using the microscope (PME3, Olympus), the pictures were taken in the reinforcing fiber direction and perpendicular to the reinforcing fiber direction.

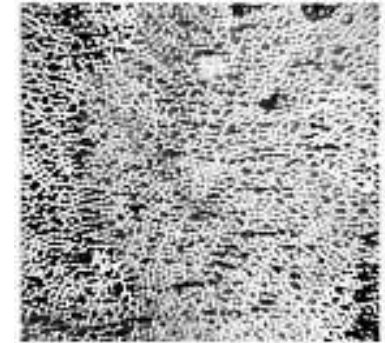

Graphite/Epoxy RT Sp. TR00/Epoxy High-Temp. Sp.

(a) perpendicular to reinforcing fiber direction

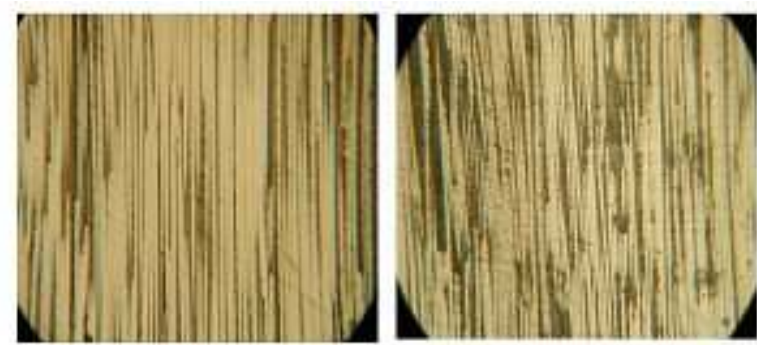

GraphiteiEpoxy RT Sp. T700Epoxy High-Temp. Sp.

Fig. 7 The microphotographs of the cut end of specimens.

From the comparison of two kinds of composites, it could be easily found that the fiber arrangement of T700/epoxy specimen was more irregular than that of graphite/epoxy specimen with just a glance of Fig. 7. For the quantitative confirmation, fiber volume fraction was calculated using image processing program with the photographs of the cut end. The data was achieved for three specimens and the data of each specimen was also measured at two different sections. The results were shown in table 3 .

Table 3 The comparison of fiber volume fraction

\begin{tabular}{|c|c|c|c|c|c|c|c|c|}
\hline$v_{f}$ & \multicolumn{2}{|c|}{ Sp.\#1 } & \multicolumn{2}{|c|}{ Sp\#2 } & \multicolumn{2}{|c|}{ Sp\#3 } & Avg. & Stdev. \\
\hline \multirow{2}{*}{$\begin{array}{c}\text { Graphite } \\
\text { /Epoxy }\end{array}$} & $\begin{array}{c}\text { Sec. } \\
\text { \#1 }\end{array}$ & $\begin{array}{c}\text { Sec. } \\
\# 2\end{array}$ & $\begin{array}{c}\text { Sec. } \\
\# 1\end{array}$ & $\begin{array}{c}\text { Sec. } \\
\text { H2 }\end{array}$ & $\begin{array}{l}\text { Sec. } \\
\text { \#1 }\end{array}$ & $\begin{array}{c}\text { Sec. } \\
\# 2\end{array}$ & \multirow{2}{*}{$52.7 \%$} & \multirow{2}{*}{1.61} \\
\hline & 51.4 & 51.7 & 51.4 & 52.1 & 54.4 & 55.0 & & \\
\hline \multirow{2}{*}{$\begin{array}{c}\text { T700 } \\
/ \text { Epoxy }\end{array}$} & $\begin{array}{l}\text { Sec. } \\
\# 1\end{array}$ & $\begin{array}{c}\text { Sec. } \\
\# 2\end{array}$ & $\begin{array}{c}\text { Sec. } \\
\# 1\end{array}$ & $\begin{array}{c}\text { Sec. } \\
\text { H2 }\end{array}$ & $\begin{array}{l}\text { Sec. } \\
\# 1\end{array}$ & $\begin{array}{c}\text { Sec. } \\
\# 2\end{array}$ & \multirow{2}{*}{$51.9 \%$} & \multirow{2}{*}{2.95} \\
\hline & 52.4 & 49.0 & 50.3 & 57.0 & 52.9 & 49.6 & & \\
\hline
\end{tabular}


From the result of table 3, the deviation of measured data from T700/epoxy was about two times as large as that of graphite/epoxy while the averages were almost the same. In short, the specimen was fabricated with the reinforcing fiber wrinkled at some parts of the specimen. Though the irregularities of the specimen were considered, the material properties at $400^{\circ} \mathrm{C}$ showed too large deviations. The reasons were analogized by the failure shapes of specimens at each temperature shown in Fig. 8. In the Fig. 8, the failure shapes of specimens at $100^{\circ} \mathrm{C}$ and $200^{\circ} \mathrm{C}$ were definitely normal. However, the marks that the matrices were burned and evaporated were found by the failure shapes of specimens at $300^{\circ} \mathrm{C}$ and $400^{\circ} \mathrm{C}$. The thermal strain induced by the matrix evaporation could have generated some measurement error of FBG sensor. Therefore, the thermal strain of FBG sensor during matrix evaporation should be also measured for the accurate measurement of material properties.

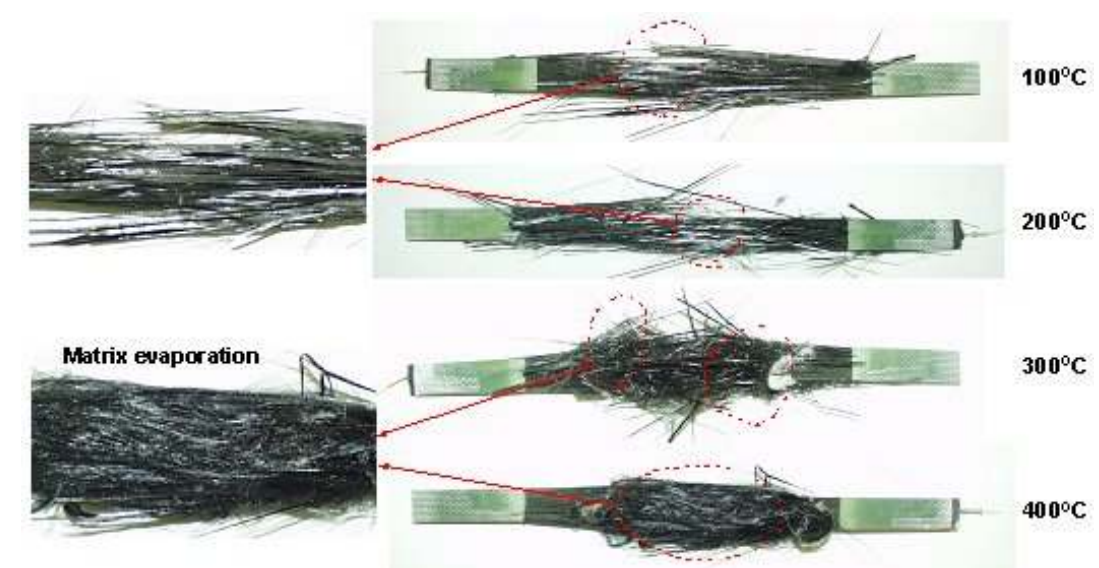

Fig. 8 Failure shapes of specimens at each temperature.

\section{Measurement of material properties at high temperature $: 90^{\circ}$ specimens}

Using the same procedure with the previous section, the material properties of $90^{\circ}$ specimens were measured and the results were shown in table 4.

Table 4 Material properties of $\left[90_{4}\right]_{\mathrm{T}}$ at high temperatures

\begin{tabular}{|c|c|c|c|c|c|c|c|c|c|c|}
\hline \multirow{2}{*}[90_{4}]{$_{T}$} & \multicolumn{2}{|c|}{ RT } & \multicolumn{2}{|c|}{$100^{\circ} \mathrm{C}$} & \multicolumn{2}{|c|}{$200^{\circ} \mathrm{C}$} & \multicolumn{2}{|c|}{$300^{\circ} \mathrm{C}$} & \multicolumn{2}{|c|}{$400^{\circ} \mathrm{C}$} \\
\hline & Avg. & Stder. & Avg. & Stder. & Aug. & Stder. & Aug. & Stder. & Avg. & Stdev. \\
\hline $\begin{array}{c}\text { Stiffness } \\
\text { [GPa] }\end{array}$ & 8.26 & 0.13 & 7.23 & 0.08 & 3.73 & 0.42 & \multirow{2}{*}{\multicolumn{2}{|c|}{$\begin{array}{c}\text { Matrix } \\
\text { evaporation }\end{array}$}} & \multirow{2}{*}{\multicolumn{2}{|c|}{$\begin{array}{c}\text { Matrix } \\
\text { evaporation }\end{array}$}} \\
\hline $\begin{array}{c}\text { Strength } \\
\text { [MPa] }\end{array}$ & 21.7 & 1.37 & 20.75 & 0.64 & 10.16 & 0.34 & & & & \\
\hline
\end{tabular}

Contrary to the results of $0^{\circ}$ specimens, both stiffness and strength decreased continuously with the increase of temperature. But, the measurement was impossible over $300^{\circ} \mathrm{C}$ because the matrix couldn't bear the load due to matrix evaporation. Material properties within $200^{\circ} \mathrm{C}$ decreased nonlinearly as the temperature increased. The tendency of material properties change was illustrated in Fig. 9. As shown in the Fig. 9, both material property changes were similar in tendency and it could be understood that the evaporation point of MY0510 epoxy resin would exist at the temperature within $300^{\circ} \mathrm{C}$ because the matrix couldn't bear the load at $300^{\circ} \mathrm{C}$.

From the above results, FBG sensors were successfully used to measure the material properties of composites under high temperature quantitatively and it was also confirmed that the thermal strain should be measured together over a particular temperature because of matrix evaporation for the accurate measurement. 

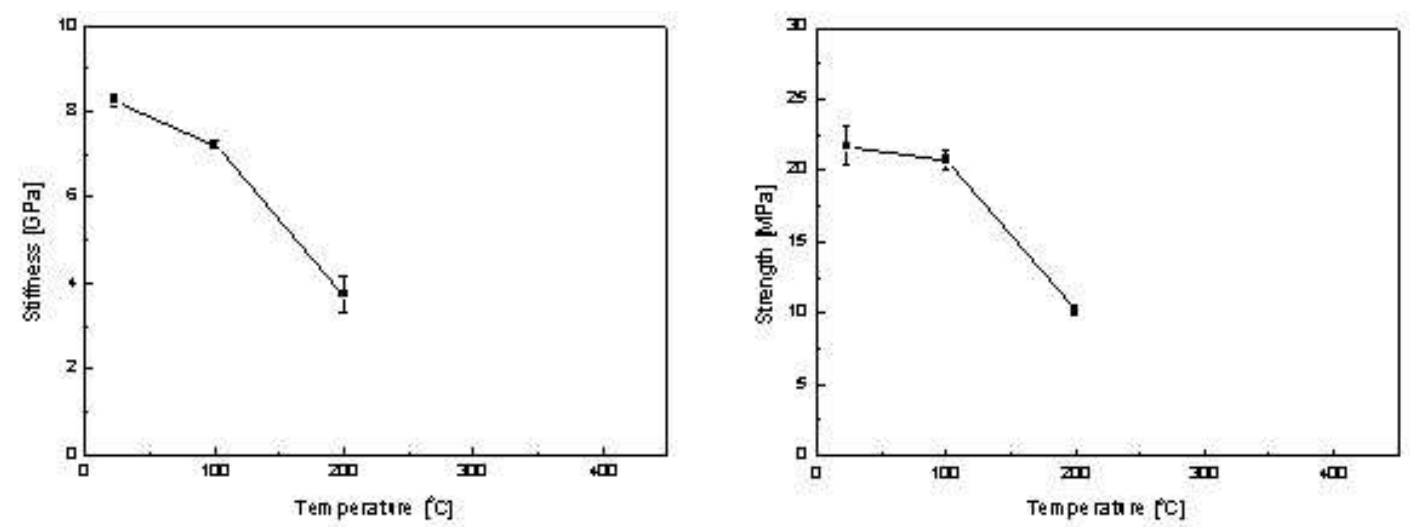

Fig. 9 Material property change of $\left[90_{4}\right]_{\mathrm{T}}$ with temperatures.

\section{Conclusion}

The conclusions in detail obtained by this research are as follows. FBG sensors are suitable and successfully adoptable to measure the material properties of composites without any degradation of material properties. The PVC jacket is the best choice of protection at ingress/egress point of composites if you consider the effectiveness of fabrication. The material properties of composites in the perpendicular direction to the reinforcing fiber as well as in the reinforcing fiber direction can be measured using embedded FBG sensors under high temperature. From the results, it can be confirmed that the FBG sensor is very appropriate to strain measurement of composites under high temperature.

\section{Acknowledgements}

The authors would like to thank to the Agency for Defense Development for assistance with funds.

\section{References}

[1] J. Rosler and M. Baker, "A Theoretical Concept for the Design of High-Temperature Materials by Dual-Scale Particle Strengthening," Acta metallurgica Inc., 2000.

[2] S. T. Mileiko and V. I. Glushko, "Fabrication and Properties of New Oxide-Based Composite Fibres (MIGL) and Heat-Resistant Materials Reinforced with Them," Composites Science and Technology, 1997, p1497-1507.

[3] H. K. Kang, J. S. Park, D. H. Kang, C. U. Kim, C. S. Hong and C. G. Kim, "Strain Monitoring of Filament Wound Composite Tank Using Fiber Optic Sensors," Smart Materials and Structures, Vol. 11, No. 6, 2002, pp. 848-853.

[4] H. K. Kang, D. H. Kang, H. J. Bang, C. S. Hong and C. G. Kim, "Cure Monitoring of Composite Laminates Using Fiber Optic Sensors," Smart Materials and Structures, Vol. 11, No. 2, 2002, pp. 279-287.

[5] D. H. Kang, H. K. Kang, C. Y. Rye, C. S. Hong and C. G. Kim, "Thermal Strain and Temperature Measurements of Structures by Using Fiber-Optic Sensors," KSAS, Vol. 28, No. 8, 2000, pp. 61-68.

[6] M. Lossie, "Production Oriented Design of Filament Wound Composites," K. U. Leuven, Ph.D Thesis, April, 1990.

[7] C. Y. Ryu, C. S. Hong, "Development of Fiber Bragg Grating Sensor System Using Wavelength-Swept Fiber Laser," Smart Materials and Structures, Vol. 11, No. 3, 2002, pp. 468-473. 
[8] S. H. Yun, D. J. Richardson and B. Y. Kim, "Interrogation of Fiber Grating Sensor Arrays with a Wavelength-Swept Fiber Laser," Optics Letters, Vol. 23, No. 11, 1998, pp. 843-845. 